Received Date : 28-Sep-2015

Revised Date : 26-Jan-2016

Accepted Date : 29-Mar-2016

Article type: Research Article

(1)

Title: Diabetic Medicine

Created by: Maria Davie

Email proofs to: asarma@umich.edu

Article no.: DME-2015-00262

Article type: Research Article

Figures:2; Tables:2; Equations:0; References: 30

Short title/Authors running head: Glycaemic control and risk of urinary incontinence $\bullet S$. M. Lenherr et al.

\title{
Research:Complications
}

Glycaemic control and risk of incident urinary incontinence

in women with Type 1 diabetes: results from the Diabetes

Control and Complications Trial and Epidemiology of

Diabetes Interventions and Complications study

(DCCT/EDIC)

S. M. Lenherr ${ }^{1}$, J. Q. Clemens ${ }^{1}$, B. H. Braffett ${ }^{2}$, R. L. Dunn ${ }^{1}$, P. A. Cleary ${ }^{2}$, C.

$\mathrm{Kim}^{3}$, W.H. Herman ${ }^{3}$, J. M. Hotaling ${ }^{4}$, A. M. Jacobson ${ }^{5}$, J. S. Brown ${ }^{6}$, H.

Wessells $^{7}$, A. V. Sarma ${ }^{1}$ and the DCCT/EDIC Research Group

${ }^{1}$ Department of Urology, University of Michigan, Ann Arbor, MI, ${ }^{2}$ Biostatistics Center, George

This is the author manuscript accepted for publication and has undergone full peer review but has not been through the copyediting, typesetting, pagination and proofreading process, which may lead to differences between this version and the Version of Record. Please cite this article as doi: $\underline{10.1111 / \text { dme.13126 }}$

This article is protected by copyright. All rights reserved 
Washington University, Rockville, MD, ${ }^{3}$ Department of Medicine, University of Michigan, Ann Arbor, MI, ${ }^{4}$ Department of Surgery, Division of Urology, University of Utah, Salt Lake City, UT, ${ }^{5}$ Winthrop University Hospital, Research Institute, Mineola, NY, ${ }^{6}$ Department of Obstetrics, Gynecology and Reproductive Sciences Urology and Epidemiology, University of California San Francisco, CA and ${ }^{7}$ Department of Urology, University of Washington School of Medicine and Harborview Medical Center, Seattle, WA, USA

Accepted

Correspondence to: Aruna V. Sarma. e-mail: asarma@umich.edu

\section{What's new?}

- Research to date has failed to show an association between glycaemic control and urinary incontinence (UI) in women with diabetes.

- We examined the relationship between $\mathrm{HbA}_{1 \mathrm{c}}$ and UI using longitudinal data from the Diabetes Control and Complications Trial (DCCT) and its observational follow-up, the Epidemiology of Diabetes Interventions and Complications (EDIC) study.

- Our findings show that the odds of UI increase with poor glycaemic control in women with Type 1 diabetes, independently of other well-described predictors of UI.

\section{Abstract}

Aims To study the impact of glycaemic control on urinary incontinence in women who participated in the Diabetes Control and Complications Trial (DCCT; 1983-1993) and its observational follow-up study, the Epidemiology of Diabetes Interventions and Complications (EDIC; 1994- present).

Methods Study participants were women who completed, at both years 10 (2003) and 17 (2010) of the EDIC follow-up, the urological assessment questionnaire (UroEDIC). Urinary incontinence was defined as self-reported involuntary leakage of urine that occurred at least weekly. Incident urinary incontinence was defined as weekly urinary incontinence present at EDIC year 17 but not at EDIC year 10. Multivariable regression models were used to examine the association of incident urinary incontinence with comorbid prevalent conditions and glycaemic control (mean $\mathrm{HbA}_{1 \mathrm{c}}$ over the first 10 years of EDIC). 
Results A total of 64 (15.3\%) women with Type 1 diabetes (mean age $43.6 \pm 6.3$ years at EDIC year 10) reported incident urinary incontinence at EDIC year 17. When adjusted for clinical covariates (including age, DCCT cohort assignment, DCCT treatment arm, BMI, insulin dosage, parity, hysterectomy, autonomic neuropathy and urinary tract infection in the last year), the mean EDIC $\mathrm{HbA}_{1 \mathrm{c}}$ was associated with increased odds of incident urinary incontinence (odds ratio $1.03,95 \%$ CI $1.01-1.06 \mathrm{per} \mathrm{mmol} / \mathrm{mol}$ increase; odds ratio $1.41,95 \%$ CI $1.07-1.89 \mathrm{per} \% \mathrm{HbA}_{1 \mathrm{c}}$ increase).

Conclusions Incident urinary incontinence was associated with higher $\mathrm{HbA}_{1 \mathrm{c}}$ levels in women with Type 1 diabetes, independent of other recognized risk factors. These results suggest the potential for women to modify their risk of urinary incontinence with improved glycaemic control.

(Clinical Trials Registry no: NCT00360815 and NCT00360893).

\section{Introduction}

Urinary incontinence (UI), or the complaint of involuntary leakage of urine, is one of the most prevalent chronic conditions in women. Although the estimated prevalence of UI varies depending on the definition applied and the age range of the population under study, on average $20-25 \%$ of women aged $40-50$ years report having UI, leading to significant distress and reduced quality of life [1]. Epidemiological studies suggest that diabetes is an independent risk factor for UI in women [2,3]. The evidence regarding the effect of poor glycaemic control on subsequent UI among women with diabetes, however, is limited and unclear. It has been hypothesized that poor glycaemic control could contribute to this problem, either acutely by causing glycosuria, or chronically, by causing neuropathy [4,5]; however, recent studies have failed to show an association between glycaemic control and UI in women with diabetes [6-9]. The studies were limited by their cross-sectional design, inclusion of women primarily with Type 2 diabetes and relatively small sample of women with poor glycaemic control.

The objective of the present study was to determine whether long-term mean $\mathrm{HbA}_{1 \mathrm{c}}$ levels among women with Type 1 diabetes were associated with UI development after accounting for established risk factors. We hypothesized that poor glycaemic control in Type 1 diabetes may result in an increased risk of UI. We examined the relationship between $\mathrm{HbA}_{1 \mathrm{c}}$ levels and UI 
using data from the Diabetes Control and Complications Trial (DCCT) and its observational follow-up, the Epidemiology of Diabetes Interventions and Complications (EDIC) study. The DCCT/EDIC study has collected detailed information on subjects with Type 1 diabetes since 1983. Information regarding UI has been collected since 2003 in an ancillary study of urological complications of diabetes (UroEDIC). Patients and methods

\section{Population and setting}

The DCCT was a multicentre, randomized clinical trial designed to compare the effects of intensive and conventional diabetes therapy on the development and progression of early microvascular and neuropathic complications of Type 1 diabetes [10]. From 1983 to 1989, 1441 patients (including 680 women) aged 13-39 years were recruited at 29 centres. The DCCT included a primary prevention cohort and a secondary intervention cohort. The primary prevention cohort included 348 women with a diabetes duration of 1-5 years at baseline, no retinopathy and a urinary albumin excretion rate $<40 \mathrm{mg} / 24 \mathrm{~h}$. The secondary intervention cohort included 332 women with diabetes duration of 1-15 years at baseline, non-proliferative retinopathy and a urinary albumin excretion rate $\leq 200 \mathrm{mg} / 24 \mathrm{~h}$. Individuals were excluded if they had hypertension, a history of symptomatic ischaemic heart disease, or the presence of symptomatic peripheral neuropathy requiring therapy. The intensive-therapy regimen was designed to achieve glycaemic control as close to the non-diabetes range as safely possible with $\geq 3$ daily insulin injections or by use of an insulin pump, with insulin dose adjustment guided by frequent self-monitoring of blood glucose. Conventional therapy consisted of 1-2 daily insulin injections without prespecified target glucose levels and aimed for absence of symptomatic hyperglycaemia or frequent or severe hypoglycaemia. At the end of the trial in 1993, after a mean follow-up of 6.5 years, the DCCT proved that intensive therapy significantly reduced the risks of microvascular complications compared with conventional treatment [11]. Intensive treatment was subsequently encouraged for all subjects, who then returned to their own healthcare providers for ongoing diabetes care.

In 1994, 655 (96\%) of the 680 surviving women (mean age $35 \pm 7$ years), volunteered to participate in the EDIC study. During EDIC year 10 (2003-2004), 550 of the 652 active female participants (84\%), agreed to participate in the UroEDIC study, an ancillary study to examine the presence of urological complications, including UI, lower urinary tract symptoms, urinary tract 
infections and sexual dysfunction. In EDIC year 17 (2010-2011), 580 of the 618 active female participants (94\%), completed the UroEDIC protocol. A total of 500 women (mean age $51 \pm 7$ years), provided information on UI at both EDIC years 10 and 17. Of these 500 women, $417 \mathrm{did}$ not report UI at EDIC year 10 and were eligible for the study of incident UI at EDIC year 17 (Fig. 1). The institutional review board of each participating centre approved the study.

\section{Measurement of urinary incontinence}

Assessment of UI was performed at EDIC years 10 and 17 with a self-administered questionnaire using validated instruments from previous studies [12]. The sequence of incontinence questions began with, 'During the past 12 months how often have you leaked even a small amount of urine...'. The frequency of incontinence was ascertained as every day, $\geq 1$ time weekly, $\geq 1$ time monthly, or $<1$ time per month. The primary outcome of interest was weekly or more frequent UI, which we defined as 'weekly UI'. Those subjects with less than weekly or no UI were defined as having 'no UI'. Among women with weekly UI, the type of incontinence during the past 7 days was classified by answers to the additional questions, '...during activities such as coughing, sneezing, lifting or exercise?" (stress incontinence) and '... with an urge to urinate and could not get to the bathroom fast enough?' (urge incontinence). Those who reported both types were placed in the category 'mixed incontinence'. Incident UI was defined by cases of weekly UI present at EDIC year 17 but not at EDIC year 10. Urinary tract infection was also assessed at EDIC years 10 and 17 by self-report with the following question, 'How many times were you diagnosed by a physician with a bladder infection in the previous 12 months?'. For the purposes of the present study, urinary tract infection at EDIC year 17 was defined as $\geq 1$ episode in the past 12 months.

\section{Diabetes measurements}

Each partipant in the EDIC study underwent an annual medical history, physical examination and laboratory testing including $\mathrm{HbA}_{1 \mathrm{c}}$, using the same methods as those used during the DCCT [13]. $\mathrm{HbA}_{1 \mathrm{c}}$ levels were measured at baseline and quarterly during the DCCT, and annually in the EDIC study using high-performance ion-exchange liquid chromatography, as previously described [14]. For the purposes of the present analysis, we used the mean $\mathrm{HbA}_{1 \mathrm{c}}$ during EDIC years 1-10 as the exposure variable. This time frame was chosen to ensure temporality of the 
$\mathrm{HbA}_{1 \mathrm{c}}$ and UI relationship, as annual UI development was not available between the years 10 and 17. Retinopathy was assessed using fundus photographs that were centrally graded using the Early Treatment Diabetic Retinopathy Study scale. The albumin excretion rate was measured in half of the cohort annually. Nephropathy was defined as an albumin excretion rate $>30 \mathrm{mg} / 24 \mathrm{~h}$. Peripheral neuropathy was defined by the Michigan Neuropathy Screening Instrument as $>6$ responses on the questionnaire or a score of $>2$ on the examination. Abnormal cardiovascular autonomic neuropathy was defined as: either R-R variation $<15$ or R-R variation between 15 and 19.9, plus either a Valsalva ratio $\leq 1.5$ or a supine-to-standing drop of $\geq 10 \mathrm{~mm} \mathrm{Hg}$ in diastolic blood pressure.

\section{Statistical analysis}

The distribution of demographic and clinical characteristics, cohort and treatment, markers of diabetes control and microvascular complications at EDIC year 10 were compared according to incident weekly UI status at EDIC year 17 using the chi-squared test for categorical variables and the Wilcoxon rank-sum test for continuous variables. A multivariable logistic regression model was used to estimate the association between glycaemic control (mean $\mathrm{HbA}_{1 \mathrm{c}}$ from EDIC year 1 to year 10) and incident weekly UI at EDIC year 17. Adjustments for a priori predictors of UI described in the literature and those that were significant in bivariate analyses were performed. The following EDIC year 10 adjustment variables were used for multivariable models: age; DCCT cohort assignment; DCCT treatment arm; EDIC mean BMI; total daily insulin dosage; parity; hysterectomy; autonomic neuropathy; and urinary tract infection in the last year. Effects nominally significant at $P \leq 0.05$ are reported. All analyses were performed using SAS version 9.3 (SAS Institute, Cary, NC, USA).

\section{Resullts}

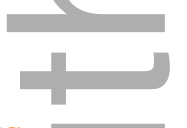

Among the 417 women who did not report at least weekly UI at EDIC year 10, 64 reported at least weekly UI at EDIC year 17 representing an incidence of weekly UI of $15.3 \%$ over this 7year time frame. These women were classified as having either mixed UI $(n=29,45.3 \%)$, stress UI $(n=27,42.2 \%)$ or urge UI $(n=5,7.8 \%)$. Type of UI was not specified by three $(4.7 \%)$ women. There were no significant differences in the characteristics of women with and without UI at EDIC year 10 with respect to age, race, parity, menopausal status, hysterectomy or urinary tract 
infection within the past year (Table 1). Mean BMI at EDIC year 10 was greater in women reporting incident UI compared with women reporting less frequent UI $(P=0.08)$. Intensive vs conventional therapy assignment during DCCT was associated with incident weekly UI during the EDIC study $(P=0.03)$, with a higher frequency of incident UI in women assigned to intensive therapy during the DCCT. The DCCT cohort (primary vs secondary) was not associated with incident weekly UI $(P=0.79)$.

Women with incident weekly UI had higher mean $\mathrm{HbA}_{1 \mathrm{c}}$ levels at EDIC year 1 [68 16 $\mathrm{mmol} / \mathrm{mol}(8.3 \pm 1.5 \%)$ vs $62 \pm 14 \mathrm{mmol} / \mathrm{mol}(7.8 \pm 1.3 \%) ; P=0.01]$ and EDIC year $10[68 \pm 15$ $\mathrm{mmol} / \mathrm{mol}(8.4 \pm 1.4 \%)$ vs $61 \pm 14 \mathrm{mmol} / \mathrm{mol}(7.8 \pm 1.2 \%) ; P=0.001]$ as compared with women who did not develop UI by EDIC year 17. Similarly, mean HbA1c up to EDIC year 10 was higher in women with incident weekly UI compared with women who did not develop UI between EDIC years 10 and $17[68 \pm 14 \mathrm{mmol} / \mathrm{ml}(8.4 \pm 1.2 \%)$ vs $63 \pm 12 \mathrm{mmol} / \mathrm{mol}(7.9 \pm$ $1.1 \%) ; P=0.003]$. Women with weekly UI also reported a higher mean daily dose of insulin during EDIC years $1-10$ ( $0.59 \pm 0.16$ vs $0.55 \pm 0.17$ units/kg/day; $P=0.03)$. The frequency of diabetes-associated microvascular complications, such as proliferative retinopathy, nephropathy, peripheral neuropathy and autonomic neuropathy, did not differ between women with and without incident weekly UI (Table 1).

A multivariable logistic regression model was used to estimate the association between unit changes in glycaemic control and incident weekly UI after adjustment for age, DCCT treatment group, DCCT cohort assignment, BMI, EDIC mean daily insulin dose, parity, hysterectomy, autonomic neuropathy and UTI (Table 2). Long-term poor glycaemic control, as defined by higher mean $\mathrm{HbA}_{1 \mathrm{c}}$ levels in EDIC years 1-10 was associated with an increased risk of UI (odds ratio 1.03 , 95\% CI 1.01-1.06 per $\mathrm{mmol} / \mathrm{mol}$ increase in $\mathrm{HbA}_{1 \mathrm{c}}$; odds ratio $1.41,95 \%$ CI $1.07-$ 1.89 per \% increase in $\mathrm{HbA}_{1 \mathrm{c}}$ ). Age, DCCT cohort assignment, DCCT treatment arm, BMI, EDIC mean insulin dosage, parity, hysterectomy, autonomic neuropathy and UTI in the last year were not significantly associated with incident $\mathrm{UI}$ independently of $\mathrm{HbA}_{1 \mathrm{c}}$. Additional analysis examining tertile distribution of $\mathrm{HbA}_{1 \mathrm{c}}$ showed an increasing risk of UI with increasing $\mathrm{HbA}_{1 \mathrm{c}}$ levels. Women with EDIC mean $\mathrm{HbA}_{1 \mathrm{c}}$ levels in the second tertile [58-67mmol $/ \mathrm{mol}(7.42-$ $8.25 \%)$ ] had a 1.44 greater odds of UI, while those with levels in the highest tertile $[\geq 67$ 
$\mathrm{mmol} / \mathrm{mol}(8.25 \%)]$ had a 2.50 greater odds of developing UI compared with women with $\mathrm{HbA}_{1 \mathrm{c}}$ levels $<58 \mathrm{mmol} / \mathrm{mol}$ (7.42\%; Fig. 2).

\section{Discussion}

The present study is the first to show the impact of glycaemic control on risk of UI among women with Type 1 diabetes. After adjustment for previously well-described risk factors, we observed a 3 and $41 \%$ increased odds of incident weekly UI associated with each $1-\mathrm{mmol} / \mathrm{mol}$ and $1 \%$ increase in $\mathrm{HbA} 1 \mathrm{c}$ level, respectively, in women with Type 1 diabetes. This association was independent of age, DCCT cohort assignment, DCCT treatment arm, BMI, insulin dosage, parity, hysterectomy, abnormal cardiovascular autonomic neuropathy and UTI in the last year. These data suggest that long-term glycaemic control may independently affect the development of UI in this population.

In contrast to the findings of the present study, previous studies have failed to identify an association between level of glycaemic control and UI [6-9]. In a study of women aged 55-75 years, enrolled in a group health plan, Jackson et al. [15] found no associations between $\mathrm{HbA}_{1 \mathrm{c}}$ (categorized as $\leq 7.5 \%, 7.6-8.5 \%$ and $>8.5 \%$ ) and UI. Similarly, Phelan et al. [7] did not observe a relationship between $\mathrm{HbA}_{1 \mathrm{c}}$ and UI among 2994 overweight/obese women with diabetes. Previous work in this cohort at EDIC year 10 also did not find an association between $\mathrm{HbA}_{1 \mathrm{c}}$ levels and prevalent UI $[16,17]$. There are several possible explanations for the discrepant findings between previous studies and the present results. First, the earlier studies included women almost exclusively with Type 2 diabetes and were limited in their cross-sectional designs. Second, these studies used measurement of $\mathrm{HbA}_{1 \mathrm{c}}$ at a single time point, a measure of current control (average glycaemic control over a period of a several months), while we used a measure of average glycaemic control over years of diabetes. Third, the average BMI in several of these studies was $>35 \mathrm{~kg} / \mathrm{m}^{2}$ and it is possible that the greater weight may have impaired the detection of the effects of these measures on UI. Interestingly in a recent report of the Diabetes and Aging Study, a sample of women with Type 1 and 2 diabetes enrolled in the Kaiser Permanente Northern California Diabetes Registry, $\mathrm{HbA}_{1 \mathrm{c}}$ level was not associated with presence or absence of UI, but poor glycaemic control, defined as $\mathrm{HbA}_{1 \mathrm{c}} \geq 9 \%$, was associated with more limitations in daily activities as a result of UI [6]. This is consistent with the present 
findings that the largest impact of glycaemic control on incident UI was among those with the highest tertile of $\mathrm{HbA}_{1 \mathrm{c}}$ levels [ $\left.>67 \mathrm{mmol} / \mathrm{mol}(8.25 \%)\right]$.

The present findings showing that poor glycaemic control is associated with UI in patients with long duration of Type 1 diabetes is consistent with effects found with other diabetes complications. Microvascular and neurological complications of Type 1 diabetes, which are established pathological consequences of poor glycaemic control $[11,18,19]$, result in changes that might damage innervation of the bladder or alter bladder muscle function, which may precipitate or worsen urinary symptoms [4,5,20,21]. Hyperglycaemia also causes increased glucosuria and urine volume, which could be a contributing factor. Improving glycaemic control has been advocated as a means of improving urinary symptoms [22].

Interestingly, we observed that those women initially randomized during the DCCT to the intensive treatment arm (as opposed to conventional treatment) have a higher incidence of weekly UI in bivariate analyses. It is possible that this is related to increased insulin exposure in the intensive treatment group, resulting in insulin-related weight gain $[23,24]$ which could cause increased intra-abdominal pressure and lead to increased bladder pressure and urethral mobility $[25,26]$. Notably, after multivariable model adjustment for mean insulin dose and BMI during the EDIC interval, the effect of randomization to intensive treatment on UI risk was no longer statistically significant. Further studies examining the complex relationship between insulin dose and effects on body size are necessary.

There are several important clinical implications for the present findings. First, the 7-year incidence (15.3\%) of weekly UI in the present study is lower than that observed for other populations $[27,28]$. While this could be a function of the variation in the definition of UI across studies, it is also possible that this is a result of improved glycaemic control, which may have contributed to the prevention of symptoms. We cannot exclude the additional possibility that women with Type 1 diabetes may be less likely to report or discuss urinary symptoms [29]. Second, for women with Type 1 diabetes our data suggest that improved glycaemic control may decrease the risk of incident UI. These findings provide a compelling argument for the routine assessment and counselling for UI in women with Type 1 diabetes. Offering women the knowledge that they can potentially decrease their risk of UI with improved glycaemic control 
might motivate some women to improve their self-care. This may be especially important given traditional treatments for UI have been found to be less effective in women with diabetes [30].

The present study is the largest examination of the impact of glycaemic control on UI in the literature among women with Type 1 diabetes. Its strengths include the minimal loss to followup and frequent validated measurement of key covariates. The long duration of follow-up allowed the exploration of long-term glycaemic control and BMI, and their relative impact on UI risk. The study also has several limitations. While the cohort has been followed for many years, participants are still relatively young and almost all are white. Also, DCCT/EDIC participants are generally a highly motivated group of individuals who have been followed for many years with a goal of good diabetes control, so these results may not apply to a broader population with Type 1 diabetes. Further, it is unclear whether these results extend to women with Type 2 diabetes, who generally have a different demographic profile from women with Type 1 diabetes, and have a later age of diabetes onset and a higher prevalence of obesity. Finally, we were unable to evaluate the impact of glycaemic control on specific types of UI because of the limited sample size and power. Further longitudinal follow-up of this cohort should enable these events to be examined.

In conclusion, the present findings show that the odds of UI increase with poor glycaemic control in women with Type 1 diabetes. This relationship is independent of other well-described predictors of UI and suggests that factors directly related to glycaemic control may be affecting urinary symptoms. Offering women the knowledge that they can potentially decrease their risk of UI with aggressive glycaemic control might motivate women to more strictly adhere to glycaemic therapies to reduce other more serious risks of diabetes sequelae.

\section{Funding sources}

The DCCT/EDIC was supported by cooperative agreement grants (1982-1993, 2012-2017), and contracts (1982-2012) with the Division of Diabetes Endocrinology and Metabolic Diseases of the National Institute of Diabetes and Digestive and Kidney Disease (current grant numbers U01 DK094176 and U01 DK094157), and through support by the National Eye Institute, the National Institute of Neurologic Disorders and Stroke, the General Clinical Research Centers Program 
(1993-2007), and Clinical Translational Science Center Program (2006-present), Bethesda, MD, USA.

Additional support for this DCCT/EDIC collaborative study (UroEDIC) was provided by an R01 grant (2009-2013) with the National Institute of Diabetes and Digestive and Kidney Diseases (5R01DK083927-03). S.M.L. is supported by NIH/NIDDK T32 DK07782.

\section{Competing interests}

None declared.

\section{Acknowledgements}

A complete list of participants in the DCCT/EDIC research group can be found in New England Journal of Medicine, 2011;365:2366-2376.

Industry contributors have had no role in the DCCT/EDIC study but have provided free or discounted supplies or equipment to support participants' adherence to the study: Abbott Diabetes Care (Alameda, CA), Animas (Westchester, PA), Bayer Diabetes Care (North America Headquarters, Tarrytown, NY), Becton Dickinson (Franklin Lakes, NJ), Eli Lilly (Indianapolis, IN), Extend Nutrition (St. Louis, MO), Insulet Corporation (Bedford, MA), Lifescan (Milpitas, CA), Medtronic Diabetes (Minneapolis, MN), Nipro Home Diagnostics (Ft. Lauderdale, FL), Nova Diabetes Care (Billerica, MA), Omron (Shelton, CT), Perrigo Diabetes Care (Allegan, MI), Roche Diabetes Care (Indianapolis, IN), and Sanofi-Aventis (Bridgewater, NJ, USA).

1. Hunskaar S, Burgio K, Diokno A, Herzog AR, Hjalmas K, Lapitan MC. Epidemiology and natural history of urinary incontinence in women. Urology 2003; 62:16-23.

2. Brown JS, Vittinghoff E, Lin F, Nyberg LM, Kusek JW, Kanaya AM. Prevalence and risk factors for urinary incontinence in women with type 2 diabetes and impaired fasting glucose: findings from the National Health and Nutrition Examination Survey (NHANES) 2001-2002. Diabetes Care 2006; 29:1307-1312.

3. Lifford KL, Curhan GC, Hu FB, Barbieri RL, Grodstein F. Type 2 diabetes mellitus and risk of developing urinary incontinence. J Am Geriatr Soc 2005; 53:1851-1857. 
4. Brown JS, Wessells H, Chancellor MB, Howards SS, Stamm WE, Stapleton AE et al. Urologic complications of diabetes. Diabetes Care 2005; 28:177-185.

5. Daneshgari F, Liu G, Birder L, Hanna-Mitchell AT, Chacko S. Diabetic bladder dysfunction: current translational knowledge. J Urol 2009; 182:S18-26.

6. Lee SJ, Karter AJ, Thai JN, Van Den Eeden SK, Huang ES. Glycemic control and urinary incontinence in women with diabetes mellitus. J Womens Health (Larchmt) 2013; 22:1049-1055.

7. Phelan S, Kanaya AM, Subak LL, Hogan PE, Espeland MA, Wing RR et al. Prevalence and risk factors for urinary incontinence in overweight and obese diabetic women: action for health in diabetes (look ahead) study. Diabetes Care 2009; 32:1391-1397.

8. Jackson SL, Scholes D, Boyko EJ, Abraham L, Fihn SD. Predictors of urinary incontinence in a prospective cohort of postmenopausal women. Obstet Gynecol 2006; 108: 855-862.

9. Ebbesen MH, Hannestad YS, Midthjell K, Hunskaar S. Diabetes related risk factors did not explain the increased risk for urinary incontinence among women with diabetes. The Norwegian HUNT/EPINCONT study. BMC Urol 2009; 9: 11.

10. Group TDCaCTR. Effect of intensive diabetes treatment on the development and progression of long-term complications in adolescents with insulin-dependent diabetes mellitus: Diabetes Control and Complications Trial. Diabetes Control and Complications Trial Research Group. J Pediatr 1994;

125: $177-188$.

11. The effect of intensive treatment of diabetes on the development and progression of long-term complications in insulin-dependent diabetes mellitus. The Diabetes Control and Complications Trial Research Group. N Engl J Med 1993; 329: 977-986.

12. Sandvik H, Hunskaar S, Vanvik A, Bratt H, Seim A, Hermstad R. Diagnostic classification of female urinary incontinence: an epidemiological survey corrected for validity. J Clin Epidemiol 1995; 48 : 339-343.

13. Nathan DM, Group DER. The diabetes control and complications trial/epidemiology of diabetes interventions and complications study at 30 years: overview. Diabetes Care 2014; 37: 9-16.

14. Epidemiology of Diabetes Interventions and Complications (EDIC). Design, implementation, and preliminary results of a long-term follow-up of the Diabetes Control and Complications Trial cohort. Diabetes Care 1999; 22: 99-111.

15. Jackson SL, Scholes D, Boyko EJ, Abraham L, Fihn SD. Urinary incontinence and diabetes in postmenopausal women. Diabetes Care 2005; 28: 1730-1738.

16. Sarma AV, Kanaya AM, Nyberg LM, Kusek JW, Vittinghoff E, Rutledge B et al. Urinary incontinence among women with type 1 diabetes-how common is it? J Urol 2009; 181:1224-1230; discussion 1230 .

This article is protected by copyright. All rights reserved 
17. Sarma AV, Kanaya A, Nyberg LM, Kusek JW, Vittinghoff E, Rutledge B et al. Risk factors for urinary incontinence among women with type 1 diabetes: findings from the epidemiology of diabetes interventions and complications study. Urology 2009; 73: 1203-1209.

18. Callaghan BC, Cheng HT, Stables CL, Smith AL, Feldman EL. Diabetic neuropathy: clinical manifestations and current treatments. Lancet Neurol 2012; 11: 521-534.

19. Edwards JL, Vincent AM, Cheng HT, Feldman EL. Diabetic neuropathy: mechanisms to management. Pharmacol Ther 2008; 120:1-34.

20. Kirschner-Hermanns R, Daneshgari F, Vahabi B, Birder L, Oelke M, Chacko S. Does diabetes mellitus-induced bladder remodeling affect lower urinary tract function? ICI-RS 2011. Neurourol Urodyn 2012; 31:359-364.

21. Yoshimura N, Chancellor MB, Andersson KE, Christ GJ. Recent advances in understanding the biology of diabetes-associated bladder complications and novel therapy. BJU Int 2005; 95:733-738.

22. Ouslander JG. Management of overactive bladder. N Engl J Med 2004; 350: 786-799.

23. Wallia A, Molitch ME. Insulin therapy for type 2 diabetes mellitus. JAMA 2014; 311: 2315-2325.

24. Intensive blood-glucose control with sulphonylureas or insulin compared with conventional treatment and risk of complications in patients with type 2 diabetes (UKPDS 33). UK Prospective Diabetes Study (UKPDS) Group. Lancet 1998; 352: 837-853.

25. Cummings JM, Rodning CB. Urinary stress incontinence among obese women: review of pathophysiology therapy. Int Urogynecol J Pelvic Floor Dysfunct 2000; 11:41-44.

26. Townsend MK, Danforth KN, Rosner B, Curhan GC, Resnick NM, Grodstein F. Body mass index, weight gain, and incident urinary incontinence in middle-aged women. Obstet Gynecol 2007; 110: 346-353.

27. Ebbesen MH, Hunskaar S, Rortveit G, Hannestad YS. Prevalence, incidence and remission of urinary incontinence in women: longitudinal data from the Norwegian HUNT study (EPINCONT). BMC Urol 2013; 13: 27.

28. Hunskaar S, Burgio K, Diokno A, Herzog AR, Hjälmås K, Lapitan MC. Epidemiology and natural history of urinary incontinence in women. Urology 2003; 62: 16-23.

29. Doshi AM, Van Den Eeden SK, Morrill MY, Schembri M, Thom DH, Brown JS. Women with diabetes: understanding urinary incontinence and help seeking behavior. J Urol 2010; 184:1402-1407.

30. Zhang YX, Xu HN, Xia ZJ, Wu B. Analysis of clinical interventional strategy for women with urinary incontinence complicated with diabetes mellitus. Int Urogynecol J 2012; 23:1527-1532. 
FIGURE 1 Flow of participants in the DCCT/EDIC/UroEDIC study. DCCT, Diabetes Control and Complications Trial; EDIC, Epidemiology of Diabetes Interventions and Complications study; UroEDIC, EDIC substudy on urological complications; UI, urinary incontinence.

FIGURE 2 Multivariable adjusted odds ratios of incident weekly urinary incontinence (UI) at Epidemiology of Diabetes Interventions and Complications study (EDIC) year 17 by tertiles of $\mathrm{HbA}_{1 \mathrm{c}}$ (EDIC mean $\mathrm{HbA}_{1 \mathrm{c}}$ up to year $10\left[\mathrm{HbA}_{1 \mathrm{c}}\right.$ reference $<58 \mathrm{mmol} / \mathrm{mol}$ or $<7.38 \%$ )]. $P$ value based on overall Wald chi-squared test for parameter estimate of $\mathrm{HbA}_{1 \mathrm{c}}$ in the multivariable logistic regression model shown in Table 2. Odds of incident weekly UI at EDIC year 17 adjusted for the following EDIC year 10 characteristics: attained age; Diabetes Control and Complications Trial (DCCT) cohort assignment; DCCT treatment group; EDIC mean daily insulin dose; EDIC mean BMI; parity; hysterectomy; autonomic neuropathy; and urinary tract infection.

Table 1. Participant characteristics at EDIC year 10 by incident weekly urinary incontinence status at EDIC year 17

\begin{tabular}{|c|c|c|c|}
\hline 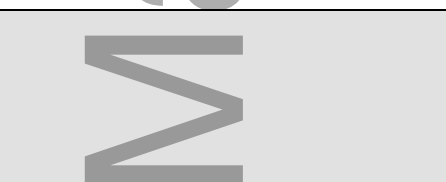 & $\begin{array}{c}\text { No UI or less } \\
\text { than weekly UI } \\
\quad(n=353)\end{array}$ & $\begin{array}{c}\text { Weekly UI } \\
\quad(n=64)\end{array}$ & $P^{*}$ \\
\hline \multicolumn{4}{|c|}{ Sociodemographic and clinical characteristics } \\
\hline Mean (SD) attained age (years) & $43.1 \pm 7.4$ & $43.6 \pm 6.3$ & 0.69 \\
\hline Smoker $\dagger, n(\%)$ & $49(14)$ & $8(13)$ & 0.77 \\
\hline Drinker $\uparrow, n(\%)$ & $125(35)$ & $23(36)$ & 0.94 \\
\hline \multicolumn{4}{|l|}{ Race, $n(\%)$} \\
\hline Non-Hispanic white & $343(97)$ & $63(98)$ & 0.53 \\
\hline Non-Hispanic black & $7(2)$ & $0(0)$ & \\
\hline Other & $3(1)$ & $1(2)$ & \\
\hline \multicolumn{4}{|l|}{ Parity ( $n$ of live births), $n(\%)$} \\
\hline 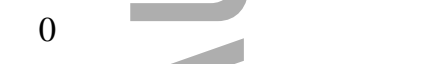 & $106(30)$ & $16(25)$ & 0.53 \\
\hline 1 & $64(18)$ & $15(23)$ & \\
\hline$\geq 2$ & $183(52)$ & $33(52)$ & \\
\hline Hysterectomy $\ddagger, n(\%)$ & $35(10)$ & $3(7)$ & 0.17 \\
\hline Postmenopausal, $n(\%)$ & $86(25)$ & $12(19)$ & 0.28 \\
\hline Mean (SD) BMI, $\mathrm{kg} / \mathrm{m}^{2}$ & & & \\
\hline
\end{tabular}




\begin{tabular}{|c|c|c|c|}
\hline EDIC mean up to year 10 & $26.3 \pm 4.1$ & $27.4 \pm 4.5$ & 0.08 \\
\hline EDIC year 10 & $27.0 \pm 4.8$ & $27.8 \pm 5.1$ & 0.27 \\
\hline Mean (SD) BMI gain during EDIC, $\mathrm{kg} / \mathrm{m}^{2}$ & $1.4 \pm 3.1$ & $1.4 \pm 3.1$ & 0.48 \\
\hline Urinary tract infection (within past year) $)^{\S}, n(\%)$ & $52(15)$ & $12(19)$ & 0.44 \\
\hline \multicolumn{4}{|l|}{ Diabetes control and treatment } \\
\hline DCCT cohort, $n$ (\% primary prevention) & $183(52)$ & $32(50)$ & 0.79 \\
\hline Treatment group, $n$ (\% intensive) & $178(50)$ & $42(66)$ & 0.03 \\
\hline \multicolumn{4}{|l|}{$\operatorname{Mean}(\mathrm{SD}) \mathrm{HbA}_{\mathrm{lc}}, \mathrm{mmol} / \mathrm{mol}$} \\
\hline EDIC year 1 & $62 \pm 14$ & $68 \pm 16$ & 0.01 \\
\hline EDIC year 10 & $61 \pm 14$ & $68 \pm 15$ & 0.001 \\
\hline EDIC mean up to year 10 & $63 \pm 12$ & $68 \pm 14$ & 0.003 \\
\hline \multicolumn{4}{|l|}{ Mean (SD) $\mathrm{HbA}_{1 \mathrm{c}}, \%$} \\
\hline EDIC year 1 & $7.8 \pm 1.3$ & $8.3 \pm 1.5$ & 0.01 \\
\hline EDIC year 10 & $7.8 \pm 1.2$ & $8.4 \pm 1.4$ & 0.001 \\
\hline EDIC mean up to year 10 & $7.9 \pm 1.1$ & $8.4 \pm 1.2$ & 0.003 \\
\hline \multicolumn{4}{|l|}{ Mean (SD) insulin dose, units/kg/day } \\
\hline EDIC year 10 & $0.60 \pm 0.23$ & $0.69 \pm 0.25$ & 0.003 \\
\hline EDIC mean up to year 10 & $0.55 \pm 0.17$ & $0.59 \pm 0.16$ & 0.03 \\
\hline \multicolumn{4}{|l|}{ Microvascular complications } \\
\hline Retinopathy ${ }^{\pi}, n(\%)$ & $50(15)$ & $10(16)$ & 0.82 \\
\hline Nephropathy $\mathbb{I}, n(\%)$ & $43(13)$ & $5(8)$ & 0.30 \\
\hline Peripheral neuropathy**, $n(\%)$ & $102(29)$ & $22(34)$ & 0.38 \\
\hline Autonomic Neuropathy ${ }^{\dagger \dagger}, n(\%)$ & $98(30)$ & $23(37)$ & 0.25 \\
\hline
\end{tabular}

DCCT, Diabetes Control and Complications Trial; EDIC, Epidemiology of Diabetes Interventions and Complications study. *P values based on the Wilcoxon rank-sum test for quantitative characteristics or the contingency chi-squared test for qualitative characteristics.

$\dagger$ Smoking was defined as 'currently smokes cigarettes or ever smoked in the past 12 months (any amount)'. Drinking was defined as 'consumed an average of at least one alcoholic beverage per week during the past 12 months' $\$$ Hysterectomy defined by report of surgically induced menopause.

§Urinary tract infection was determined at EDIC year 10 by self-report with the following question, 'How many times were you diagnosed by a physician with a 'bladder infection' in the previous 12 months?'. Urinary tract infection was defined as $\geq$ episode in past 12 months.

"Defined up to EDIC year 10 using the Early Treatment Diabetic Retinopathy Study on a scale of 0-23. Proliferative diabetic retinopathy is defined as $\geq 12$ and/or scatter or focal laser.

II Defined at EDIC year 9/10 as albumin excretion rate $(\mathrm{mg} / 24 \mathrm{~h})>30$.

** Defined at EDIC year 10 by the Michigan Neuropathy Screening Instrument $>6$ responses on the questionnaire or a score of $>2$ on the examination. 
${ }^{\dagger}{ }^{\dagger}$ Defined at EDIC year 13/14 as R-R variation $<15$ or RR variation $<20$ in combination with a Valsalva ratio $\leq 1.5$ or a decrease of $>10 \mathrm{~mm} \mathrm{Hg}$ in diastolic blood pressure upon standing.

Table 2 Adjusted multivariable logistic regression model examining the effect of glycaemic exposure on incident weekly urinary incontinence status at EDIC year 17

\begin{tabular}{|c|c|c|}
\hline Risk factors at EDIC year 10 & Odds ratio $(95 \% \mathrm{CI})$ & $\boldsymbol{P}$ \\
\hline Attained age (per year) & $1.02(0.97,1.06)$ & 0.53 \\
\hline DCCT cohort (primary prevention vs secondary intervention) & $0.90(0.50,1.64)$ & 0.74 \\
\hline DCCT treatment group (intensive vs conventional) & $1.71(0.92,3.19)$ & 0.09 \\
\hline EDIC mean BMI up to year $10\left(\mathrm{~kg} / \mathrm{m}^{2}\right)$ & $1.05(0.97,1.12)$ & 0.21 \\
\hline EDIC mean insulin dose up to year 10 (units/kg/day) & $3.01(0.50,18.22)$ & 0.23 \\
\hline \multicolumn{3}{|l|}{ Parity ( $n$ of live births) } \\
\hline & $1.79(0.75,4.27)$ & 0.23 \\
\hline$\geq 2$ vs 0 & $1.33(0.63,2.83)$ & 0.99 \\
\hline Hysterectomy (yes vs no) & $0.31(0.08,1.21)$ & 0.09 \\
\hline Autonomic neuropathy (yes vs no) & $1.03(0.51,2.08)$ & 0.93 \\
\hline Urinary tract infection (within past year) (yes vs no) & $1.34(0.62,2.91)$ & 0.46 \\
\hline EDIC mean $\mathrm{HbA}_{1 \mathrm{c}}$ up to year $10(\mathrm{mmol} / \mathrm{mol})$ & $1.03(1.01,1.06)$ & 0.02 \\
\hline EDIC mean $\mathrm{HbA}_{1 \mathrm{c}}$ up to year $10(\%)$ & $1.41(1.07,1.89)$ & 0.02 \\
\hline
\end{tabular}

DCCT, Diabetes Control and Complications Trial; EDIC, Epidemiology of Diabetes Interventions and Complications study.

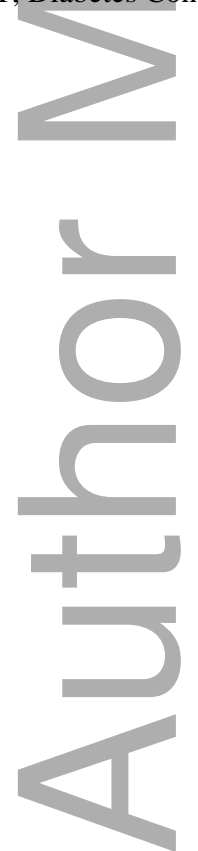


Table 1. Participant Characteristics at EDIC year 10 by incident weekly UI status at EDIC year 17

\begin{tabular}{|c|c|c|c|}
\hline 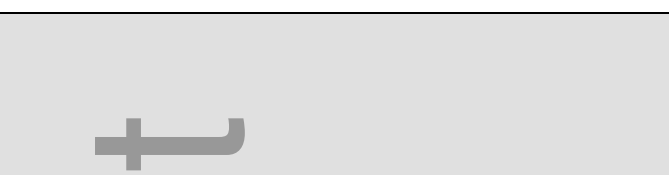 & $\begin{array}{l}\text { No UI or less } \\
\text { than weekly UI } \\
(n=353)\end{array}$ & $\begin{array}{l}\text { Weekly UI } \\
\qquad(n=64)\end{array}$ & p-value ${ }^{*}$ \\
\hline \multicolumn{4}{|l|}{ Sociodemographic and clinical } \\
\hline Attained age (years) Mean (SD) & $43.1 \pm 7.4$ & $43.6 \pm 6.3$ & 0.69 \\
\hline Smoker No. $(\%) \dagger$ & $49(14)$ & $8(13)$ & 0.77 \\
\hline Drinker No. $(\%) \dagger$ & $125(35)$ & $23(36)$ & 0.94 \\
\hline \multicolumn{4}{|l|}{ Race No. (\%) } \\
\hline Non-Hispanic White & $343(97)$ & $63(98)$ & 0.53 \\
\hline Non-Hispanic Black & $7(2)$ & $0(0)$ & \\
\hline Other & $3(1)$ & $1(2)$ & \\
\hline \multicolumn{4}{|l|}{ Parity (n of live births) No. (\%) } \\
\hline 0 & $106(30)$ & $16(25)$ & 0.53 \\
\hline 1 & $64(18)$ & $15(23)$ & \\
\hline$\geq 2$ & $183(52)$ & $33(52)$ & \\
\hline Hysterectomy No. (\%) ‡ & $35(10)$ & $3(7)$ & 0.17 \\
\hline Postmenopausal No. (\%) & $86(25)$ & $12(19)$ & 0.28 \\
\hline \multicolumn{4}{|l|}{ BMI $\left(\mathrm{kg} / \mathrm{m}^{2}\right)$ Mean (SD) } \\
\hline EDIC Mean through Year 10 & $26.3 \pm 4.1$ & $27.4 \pm 4.5$ & 0.08 \\
\hline EDIC Year 10 & $27.0 \pm 4.8$ & $27.8 \pm 5.1$ & 0.27 \\
\hline BMI Gain during EDIC $\left(\mathrm{kg} / \mathrm{m}^{2}\right)$ Mean (SD) & $1.4 \pm 3.1$ & $1.4 \pm 3.1$ & 0.48 \\
\hline UTI (within past year) No. (\%) § & $52(15)$ & $12(19)$ & 0.44 \\
\hline \multicolumn{4}{|l|}{ Diabetes control and treatment } \\
\hline DCCT cohort No. (\% primary prevention) & $183(52)$ & $32(50)$ & 0.79 \\
\hline Treatment group No. (\% intensive) & $178(50)$ & $42(66)$ & 0.03 \\
\hline \multicolumn{4}{|l|}{ Hemoglobin A1c (mmol/mol)) Mean (SD) } \\
\hline EDIC Year 1 & $62 \pm 14$ & $68 \pm 16$ & 0.01 \\
\hline EDIC Year 10 & $61 \pm 14$ & $68 \pm 15$ & 0.001 \\
\hline EDIC Mean through Year 10 & $63 \pm 12$ & $68 \pm 14$ & 0.003 \\
\hline \multicolumn{4}{|l|}{ Hemoglobin A1c (\%) Mean (SD) } \\
\hline EDIC Year 1 & $7.8 \pm 1.3$ & $8.3 \pm 1.5$ & 0.01 \\
\hline EDIC Year 10 & $7.8 \pm 1.2$ & $8.4 \pm 1.4$ & 0.001 \\
\hline EDIC Mean through Year 10 & $7.9 \pm 1.1$ & $8.4 \pm 1.2$ & 0.003 \\
\hline \multicolumn{4}{|l|}{ Insulin Dose (units/kg/day), Mean (SD) } \\
\hline EDIC Year 10 & $0.60 \pm 0.23$ & $0.69 \pm 0.25$ & 0.003 \\
\hline
\end{tabular}

This article is protected by copyright. All rights reserved 


$\begin{array}{lccc}\text { EDIC Mean through Year 10 } & 0.55 \pm 0.17 & 0.59 \pm 0.16 & 0.03 \\ \text { Microvascular complications } & & & \\ \text { Retinopathy No. (\%) II } & 50(15) & 10(16) & 0.82 \\ \text { Nephropathy No. (\%) ๆ } & 43(13) & 5(8) & 0.30 \\ \text { Peripheral Neuropathy No. (\%) \# } & 102(29) & 22(34) & 0.38 \\ \text { Autonomic Neuropathy No. (\%) ** } & 98(30) & 23(37) & 0.25\end{array}$

${ }^{*}$ P-values based on the Wilcoxon rank-sum test for quantitative characteristics or the contingency chi-square test for qualitative characteristics.

† Smoking is defined as "currently smokes cigarettes or ever smoked in the past 12 months (any amount)." Drinking is defined as "consumed an average of at least one alcoholic beverage per week during the past 12 months."

$\ddagger$ Hysterectomy defined by report of surgically induced menopause.

$\S$ Urinary tract infection (UTI) was determined at EDIC year 10 by self-report with the following question "how many times were you diagnosed by a physician with a "bladder infection" in the previous 12 months?" UTI defined as $\geq 1$ episode in past 12 months.

II Defined through EDIC year 10 using the Early Treatment Diabetic Retinopathy Study on a scale of 0-23. Proliferative diabetic retinopathy is defined as $\geq 12$ and/or scatter or focal laser.

If Defined at EDIC year 9/10 as Albumin Excretion Rate (mg/24hr) $>30$.

\# Defined at EDIC year 10 by the Michigan Neuropathy Screening Instrument $>6$ responses on the questionnaire or a score of $>2$ on the exam.

** Defined at EDIC year 13/14 as R-R variation $<15$ or RR variation $<20$ in combination with a Valsalva ratio $\leq 1.5$ or a decrease of $>10 \mathrm{~mm} \mathrm{Hg}$ in diastolic BP upon standing.

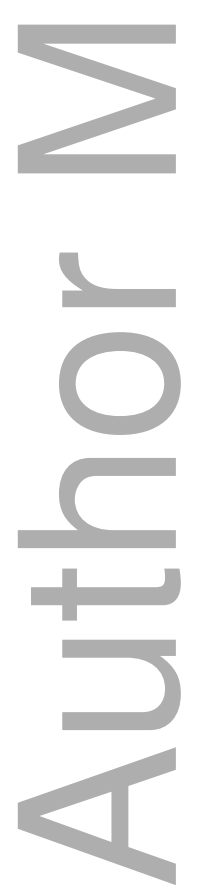

This article is protected by copyright. All rights reserved 
Table 2. Adjusted multivariable logistic regression model examining the effect of glycemic exposure on incident weekly UI status at EDIC year 17

\begin{tabular}{|lcc|}
\hline Risk Factors at EDIC Year 10 & OR (95\% Cl) & p-value \\
Attained age (per year) & $1.02(0.97,1.06)$ & 0.53 \\
DCCT cohort (primary prevention vs. secondary intervention) & $0.90(0.50,1.64)$ & 0.74 \\
DCCT treatment group (intensive vs. conventional) & $1.71(0.92,3.19)$ & 0.09 \\
EDIC mean BMI through Year 10 $\left(\mathrm{kg} / \mathrm{m}^{2}\right)$ & $1.05(0.97,1.12)$ & 0.21 \\
EDIC mean Insulin Dose through Year 10 (units/kg/day) & $3.01(0.50,18.22)$ & 0.23 \\
Parity (n of live births) & & \\
1 vs. 0 & $1.79(0.75,4.27)$ & 0.23 \\
$\geq 2$ vs. 0 & $1.33(0.63,2.83)$ & 0.99 \\
Hysterectomy (yes vs. no) & $0.31(0.08,1.21)$ & 0.09 \\
Autonomic Neuropathy (yes vs. no) & $1.03(0.51,2.08)$ & 0.93 \\
UTI (within past year) (yes vs. no) & $1.34(0.62,2.91)$ & 0.46 \\
EDIC mean HbA1c through Year $10(\mathrm{mmol} / \mathrm{mol})$ & $1.03(1.01,1.06)$ & 0.02 \\
EDIC mean HbA1c through Year $10(\%)$ & $1.41(1.07,1.89)$ & 0.02 \\
\hline
\end{tabular}

This article is protected by copyright. All rights reserved 
Figure 1. Flow of female participants in DCCT/EDIC/UroEDIC

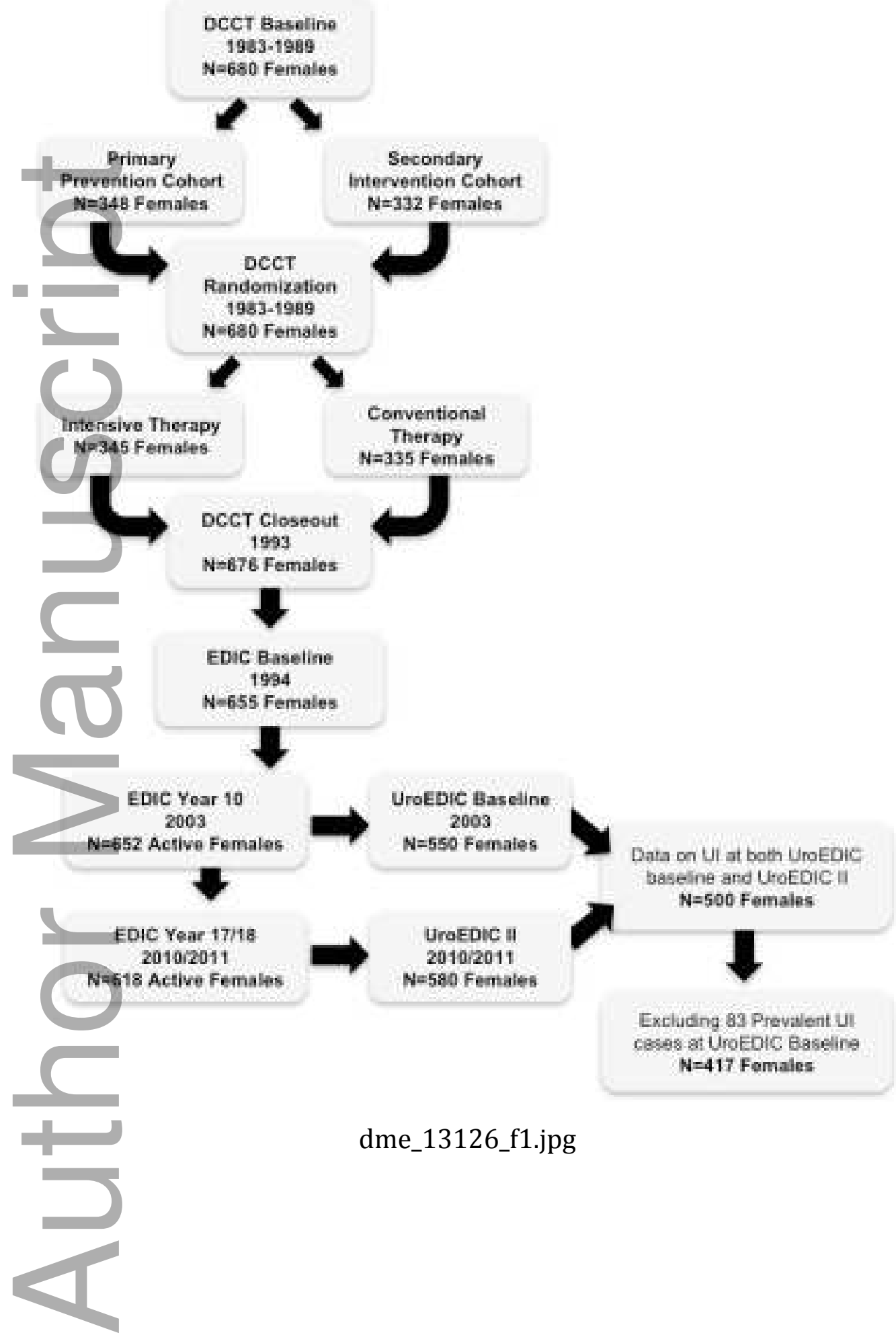

This article is protected by copyright. All rights reserved 


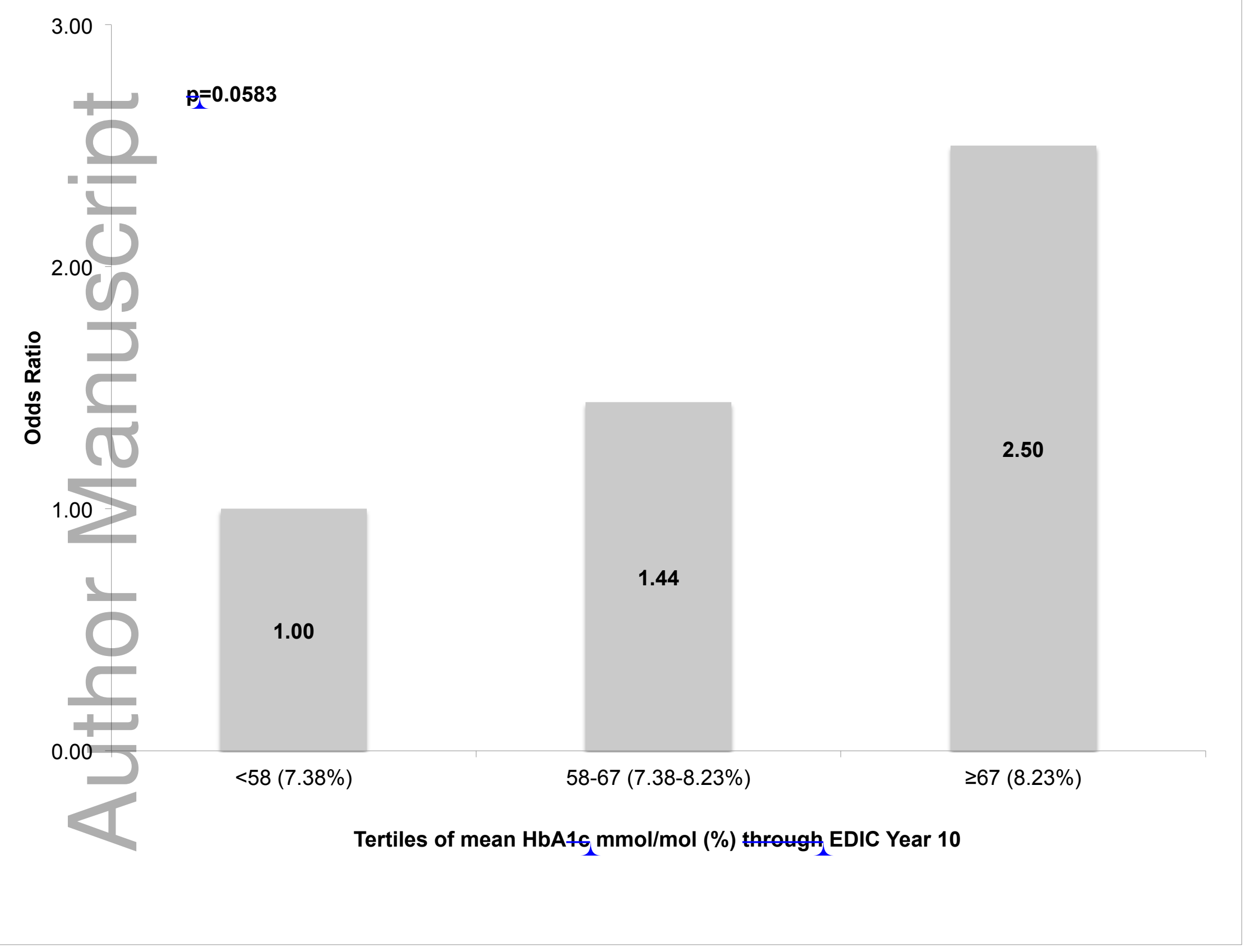

This article is protected by copyright. All rights reserved 